\title{
Promoting Democratic Society through Creative Industry
}

\author{
Lavinsa Ngestipurba, Nurul Ami W and Mr.Supriyanto \\ Universitas Diponegoro, Prof. H. Soedarto Street, Tembalang, Semarang, Indonesia \\ lavinsa.ngestipurba@yahoo.com, \{nurul.ami.w,supriyanto034\}@gmail.com
}

Keywords: Promotion, democracy society, creative industry.

\begin{abstract}
Creative economy has a significant difference from other types of businesses. Important characteristics of this sector include originality, skill, and the quality of products. Due to the creative development in a society, creative economy becomes a new emerging sector. This aim of this research is to analyze the promotion of a democratic economy through the creative industries. This research is mainly analyzing the synergy between the creative economy and tourism sector. As the creative economy is based on the processing of individual ideas, creativity, and skills to develop a sustainable economy, developing creative industries in Indonesia would not be easy. From the study, we can find that there is a visible gap to fix the deficiencies in achieving the desired goals.
\end{abstract}

\section{INTRODUCTION}

Creative industry emerges as an effort with the use of human creativity (Bilton, 2004). Creative economy has a significant difference from other types of businesses. Due to the creative development in a society, the creative economy becomes a new emerging sector. Nowadays, this type of businesses is increasing in Indonesia. The sector plays a major part in the economy as it is able to absorb more labor as well as to contribute as the second largest foreign investment after the manufacturing sector. As a country with the fourth largest population in the world, the prospects for creative industries in Indonesia are very promising. Other supporting prospects are the natural resources the country has. Being seen as a major potential, the Indonesian government declared the year 2018 as a creative year. The emergence of creative industry can help the local product to reach higher selling value, making the competition with foreign commodity much easier. Local economic actors were able to participate in the market through strict quality control, services, and brand position. The latter, however, need to be developed more to get even better results.

The democratic society provides an absolute policy. On the practice, however, there are no such policy. The community is expected to have the ability to build and work individually in the implementation process. They are mostly ignoring the rules that they have made together without any mutual harm (Pratt, 2005).

The development of the creative industry can be seen through the increasing products within the creative industries in the fields of fashion, music, and film. In the area of fashion, the success of The 3rd Indonesia Fashion Week was able to attract 527 exhibitors and 128 buyers from Malaysia, Singapore, France, Germany, USA, Sri Lanka, India, Taiwan, Thailand, and China. The number of the event's visitors reached 79,663 people, both domestic and international.

The creative industry has a very important role within the economy of a country, not only in Indonesia. This role cannot be separated as it has the ability to improve both the national and local economy. The creative industry is closely related to the level of human creativity as the main source of economic advantage. The growing number of creative industry sectors is a result of the creativity and innovation development.

The importance of this activity is motivated by Indonesia's cultural heritage and various natural sources as its comparative advantage. With the lack of attention and management skill, the sector is not well operated and decreasing its economic value, all while the creative sector has a wider market share and interest in the public. 


\section{METHODS}

This study is using secondary data. The data source is collected through documentation and reviewing a collection of previous journals. This study uses a qualitative descriptive research method. The method is used to develop theories from the data obtained by the researchers in the field. The qualitative method consists of exploring, conducting in-depth data collection from observation, and a preparation report.

\section{RESULTS AND DISCUSSIONS}

A democratic society is a society with mutual resp ect for differences. Therefore, to respect each other's differences, one must be careful not to harm those differences. The existence of globalization has fundamentally raised the prestige of democracy in the eyes of the public. The evidence can be seen from the increasing number of countries with the democratic system. However, the existence of globalization actually degrades the quality of the democracy. The application of democracy is not only seen through the increasing number of people's participation in Election and the eradication of the dictatorial system. It is also seen from the improvement of the society's living standard. With the wave of globalization, the number of inequality in society is climbing, especially with the lack of attention to the rights of workers (Garnham, 2005).

The creative industry is an industry that utilizes individual creativity as the main product as an economic advantage. The actors may vary from craftsmen, designers, architects, and the others. The creative industry does neither require a largescale production nor manufacturing industry as it relies more on the quality and creativity of its human resources. Therefore, the creative industry can grow bigger than those of a Small and Medium Enterprise. An interesting fact about the creative industry is it can affect the community to be more independent and employable (Uricchio, 2004).

Indonesia has a large opportunity in the development of the creative business industry. In several cities of Indonesia, the creative industry is developing rapidly as shown by the increasing number of new creative industries that emerge in the market. Bandung, for example, is known as a creative industry center and famous for its clothing line business. Different from Bandung, Bali is famous for its natural beauty products. Particularly, Bali also has tourism sectors that play an important role in its regional economy. Therefore, both of these sectors are developed continuously to achieve higher revenue.

Other cities in Indonesia also have their own unique advantages that cannot be compared with one another. In addition, Indonesia also has cultural richness as its National advantage, for example in the form of dancing, singing, traditional buildings, and traditional rituals. We need to preserve this culture in order to face the globalization era. With this cultural treasure, Indonesia has the advantage to create something with high selling value. Especially, when the cultural sector is already being recognized by the other countries. The development of creative industries in this sector needs to be intensified to increase local income, in addition also to preserve our culture (Mommaas, 2004).

\subsection{Ways to Promote Creative Industry}

In developing the creative industries in Indonesia, there are numerous challenges to be faced. Firstly, although Indonesia has a large number of population and natural resources, its productivity is still low compared to other Asian countries such as China, Singapore and Japan (Cunningham, 2004). This happens due to the lack of the Government's support in the following sector. Looking at the facts on the field, the Government is mostly prioritizing the development within the manufacturing sector all while the creative industry sector has the ability to absorb the same labor as the manufacturing industry (Miles and Sullivan, 2012). Secondly, Indonesians are lacking the capital to run a business. Most Indonesians are still living below the poverty line. Most of the times, their creativity is hampered by their lack of capital, making their business to fail. Only a few will survive with limited funds. In this case, the country has not yet possessed the capability to integrate the capital for the creative sector. Therefore, financial support is highly needed to develop this industry. The latter is then expected to create new types of business that can help in improving the welfare of the community (Hesmondhalgh dan Pratt, 2005). 
Table 1: Ways to Promote Creative Industry

\begin{tabular}{|c|c|}
\hline Promotion media & Percentage Amount \\
\hline Social Media & $53,72 \%$ \\
\hline Website & $28,25 \%$ \\
\hline Brochure & $28,04 \%$ \\
\hline Outdoor Media & $25,88 \%$ \\
\hline Exhibition & $24,12 \%$ \\
\hline Others & $23,88 \%$ \\
\hline
\end{tabular}

Creative business actors generally sell their products directly to the consumers, making the market still stays in the domestic territory. Furthermore, the phenomenon of the Digital Economy has influenced most businesses as they mostly use social media as a form of promotional tools.

\subsection{Sustainability of Promoting Creative Industries}

The problems, however, cannot be solved immediately. Measures must be taken to maintain the sustainability of creative industries in the country through product protections, tax exemptions, training, easy to obtain development funds, and providing promotional and marketing tools. In addition, the promotions should embrace an entire community. Promotion is an important activity which plays an active role in introducing the benefits of a product and encouraging the consumers to purchase the product. To conduct a promotion, every company must first determine which promotional tools are to be used in the activity.

According to Chatterjee et al (2016), promotion is a flow of information or one-way persuasion directly from a person or an organization that creates a marketing exchange. The methods used in the promotional activities consist of advertising, sales promotion, individual sales, and public relations. Promotion refers to various activities that the company undertakes to communicate its product in order to persuade target customers to purchase it. In conclusion, the basis of promotional activities is to communications with the consumers to in order to improve the sales (Bilton and Leary, 2004).

The government also needs to encourage people to buy local products. For example, requirements for civil servants to wear batik during several events. This will become a new platform for promoting new products and to raise people's awareness. When it is done continuously, the world community would not only aware of batik, but also other local products that have an excellent quality (Galloway and Dunlop, 2007).

We still have to appreciate the role of government in advancing this sector since the year 2009. As an example, the country now has an advantage in creating furniture based on rattan and water hyacinth. These efforts cannot be separated from the government's role in boosting the creative economy sector intensively. In terms of promoting new products, the role of the media is also necessary. The media has a role as a liaison between the sellers and buyers. In advancing the creative industry the role of the media is as important as the nation (Cunningham, 2004).

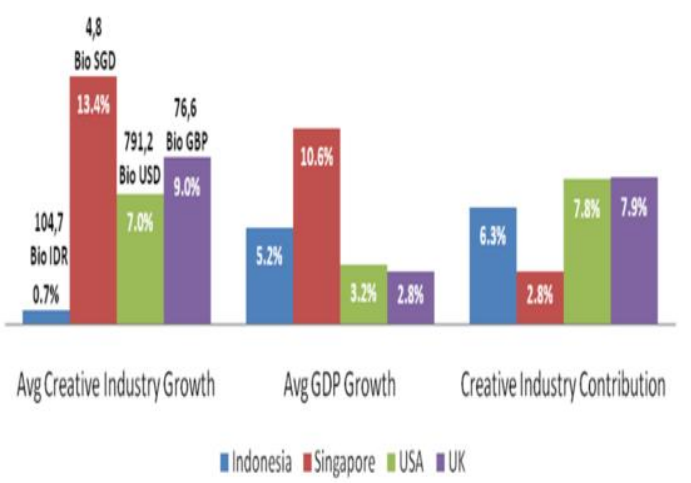

Figure 1: Creative Industry Growth.

Democracy is a form of a state's system with a purpose to facilitate the sovereignty of the people. One of the pillars of democracy is the principle of trias politica that divides the state into three political powers (executive, judicial and legislative). These state institutions are mutually independent and are equal to one another. The independence of the institutions is necessary in order to supervise the system based on the principle of checks and balances. These institutions are parts of government agencies that have the same authority to influence the nation.

Under the democratic system, legislative decisions were made by the public through the representatives of the legislative body. They are obliged to gather the aspirations of the communities they represent. They were chosen through Legislative Election. Not all citizens have the right to vote. In the Election, they have some eligibility for the citizen in order to participate. The sovereignty of the people referred here is not in the sense of their electoral vote only. 


\section{CONCLUSIONS}

The creative economy is an industry that requires creativity, talent, and the ability of individuals to create welfare and employment. The actors in this industry include crafts maker, writer, musician, performer, cook, and many others. The creative economy industry has the potential to become an alternative to help in developing the economic sector.

There are many opportunities that can be used to face the problem with the development of the creative economy sector. One of them is to stimulate the market and develop other alternative industries. Creative economy industry can be a sector that can achieve National success. The creative economy can help develop the people's ideas, creativity, and skills for a sustainable economy. To further develop the creative industries in Indonesia is indeed not easy. In order to do that, all actors both the Governments and the communities, need to work together efficiently and extensively.

The actors within the creative industry need to consider and evaluate their knowledge insights in developing the cultural sector. The reluctant habit of sharing is the main problem in the creative industry. The problem is due to the inability of the employer to deliver their knowledge. This can cause the employees' desire to seek for knowledge to decline. The lesson that needs to be taken by these actors is the Knowledge Management (KM) that changes from conventional models into a systematic and programmed model. The programs have an aim to acquire knowledge, disseminating knowledge from discussion or a forum, and storing knowledge through documentation or reports in order to develop the creative industry even further.

\section{REFERENCES}

Bilton, C. \& Leary, R. (2004). What can managers do for creativity? Brokering creativity in the creative industries. International Journal of Cultural Policy, vol. 8, no. 1, pp. 49-64.

Cunningham, S. (2004). The creative industries after cultural policy. International Journal of Cultural Studies, 7: 105-15.

Galloway, S.,dan Dunlop, S. (2007). A critique of definition of the cultural and creative industries in public policy. International Journal of Cultural Policy, 13(1): 17-31.

Garnham, N. (2005). From cultural to creative industries: an analysis of the implications of the 'creative industries' approach to arts and media policy making in the United Kingdom. International Journal of Cultural Policy.' 11(1): 15-29.

Hesmondhalgh, D. \& Pratt, A. C. (2005). Cultural industries and cultural policy. International Journal of Cultural Policy, vol. 11, no. 1, pp. 1-13.

Miles, A. and Sullivan, A. (2012). Understanding participation in culture and sport: mixing methods, reordering knowledge. Cultural Trends.' 21(4): 311324.

Mommaas, H. (2004). Cultural clusters and the postindustrial city: Towards the remapping of urban cultural policy. Urban Studies, vol. 41, no. 3, pp. 507-532.

Pratt, A. C. (2005). Cultural industries and public policy: An oxymoron? International Journal of Cultural Policy, vol. 11, no. 1, pp. 31-44.

Chatterjee, K., Krishnendu A., Srimani S., and Samarjit K. (2016). Identification and Analysis of Factors Affecting Consumer Behavior in Fast Moving Consumer Goods Sector. Business Perspectives. ISSN: 09727612.

Uricchio, W. (2004). Beyond the great divide, collaborative networks and the challenge to dominant conceptions of the creative industries. International Journal of Cultural Studies, vol. 7, no. 1, pp. 79-90. 